\title{
First-year medical student attitudes about general practice in China: a comparison between Chinese and international students
}

This article was published in the following Dove Press journal:

Advances in Medical Education and Practice

\author{
Qi Chen' \\ Siqing Lian ${ }^{2}$ \\ Melissa A Plegue ${ }^{3}$ \\ Michael D Fetters ${ }^{3,4}$ \\ 'School of Health Humanities, Peking \\ University Health Science Center, Beijing, \\ People's Republic of China; ${ }^{2}$ Peking \\ University First Hospital, Beijing, People's \\ Republic of China; ${ }^{3}$ Mixed Methods \\ Program, Department of Family \\ Medicine, University of Michigan, Ann \\ Arbor, MI, USA; ${ }^{4}$ Peking University \\ Health Science Center, Beijing, People's \\ Republic of China
}

Video abstract

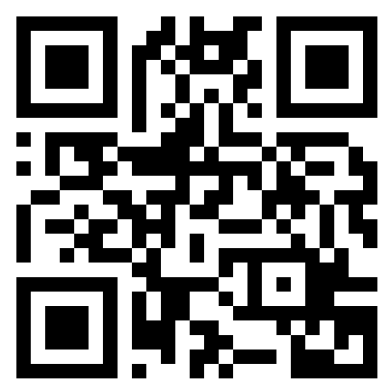

Point your SmartPhone at the code above. If you have a $Q R$ code reader the video abstract will appear. Or use: https://youtu.be/nCOCm6dzpc4

Correspondence: Michael D Fetters Mixed Methods Program, Department of Family Medicine, University of Michigan,

1018 Fuller Street, Ann Arbor, MI 48I04-

1213 , USA

Tel +l 7349984978

Fax +I 7349987335

Email mfetters@umich.edu
Introduction: Chinese policy increasingly emphasizes growth of general practice (GP). The purpose of this research was to understand attitudes toward GP among first-year Chinese and international medical students studying in China.

Methods: Based on a cross-sectional survey using a 5-point Likert scale of medical students at Peking University Health Science Center regarding attitudes toward specialty choice, practice setting, care of patient age groups, care types, and GP, we compared responses of Chinese and international medical students.

Results: In total, 258 national and 77 international students participated. International students ranked equally or more highly as favorable practice settings associated with GP, eg, outpatient $(P=0.05)$ and home care $(P<0)$, types of care associated with GP, eg, preventive services $(P<0)$ and palliative care $(P=0.01)$, and age-groups of interest, eg, care for babies $(P<0)$, children $(P<0)$, and adult women $(P=0.03)$. Chinese students more strongly endorsed beliefs that GP physicians are needed in rural Chinese areas $(P<0)$, supported by the government $(P=0.02)$, and respected by society $(P<0)$.

Discussion: Chinese students' attitudes about the social desirability of GP are consistent with Chinese policy, but international students more strongly endorsed desirable work characteristics of actual GP. These differences accentuate the need for more attention in the medical curriculum to educate Chinese students about why GP can be a personally rewarding career.

Keywords: general practice, family medicine, attitude, undergraduate medical education, general practitioner, family physician, China

\section{Introduction}

Barbara Starfield's work demonstrates that countries with robust primary health care systems are the most cost-effective. ${ }^{1-3}$ As such, understanding factors affecting student perspectives on a career in family medicine and general practice (GP) and intervening to increase student choice of GP are imperative. The medical education literature has demonstrated that personal characteristics and experiences prior to medical school influence medical student specialty preference. ${ }^{4-8}$ In multiple countries, connections to a rural community predicted interest practicing there. ${ }^{8-10}$ Previous findings reported country-specific associations with GP-specialty preferences, eg, female sex in Germany, ${ }^{11}$ medical lifestyle in Canada, ${ }^{10}$ and having a family member in GP in Japan. ${ }^{7}$ Conviction based on personal experience with illness in oneself or others has been shown to influence GP career choice, ${ }^{7,11}$ though 
expectations for higher income, prestige, and a research career have been negatively associated with primary care interest. ${ }^{4}$ Student attitudes toward GP have been illustrated to be more positive in countries with social policies favoring primary care, eg, the UK and Spain, ${ }^{6,12}$ than countries without primary care-supportive policies, eg, Brazil and Germany. ${ }^{13,14}$

\section{General practice in China}

Despite its physical and political enormity, GP education in China has received relatively little attention in the international literature. In 2010, the government adopted a globally unprecedented political commitment to develop and massively expand family medicine under the rubric of quanke yixue, translated as "general practice", to meet the health care needs of the country with the world's largest population. ${ }^{15}$

In 2010 , when there were 84,800 general practitioners (GPs) in China, ${ }^{16}$ the Chinese government targeted growth to two to three GPs per 10,000 population - 300,000 GPs by 2020 - an audacious vision requiring 213,600 new GPs in a decade. ${ }^{17}$ In 2015 , there were 188,649 GPs, $6.21 \%$ of $3,039,135$ physicians that year. ${ }^{18}$ On January 24,2018 , the Chinese State Council announced a new target for 2030 of 500,000 new GPs for 700,000 total and a ratio of five GPs per 10,000 population. ${ }^{19}$ These numerical advances aside, there are problems in quality, eg, public perceptions that GP quality is substandard ${ }^{20}$ community health centers lacking adequate equipment, ${ }^{21}$ quality of the training as suspect due to significant heterogeneity due to multiple pathways for becoming a GP, ${ }^{22}$ and GPs having poor pay and low prestige.

\section{Previous research on impact of curricula/ courses on medical student attitudes toward general practice in China}

Yong et al surveyed third-, fourth-, and fifth-year undergraduate students at a single medical school and found students on a GP-specialty track had more favorable attitudes toward community health service. ${ }^{23}$ Sun et al (2004) found that a standardized GP curriculum implemented in two schools, was associated with $90 \%$ of students responding that general medical education was important. ${ }^{24} \mathrm{Hu}$ et al randomized 60 students to an intervention arm featuring community-oriented medical education and 59 students to a control arm focusing on traditional biomedical coursework without information on GP, and found that $100 \%$ of students from the intervention versus $66.1 \%$ of control students felt that community-oriented medical education was necessary. ${ }^{25}$

\section{Previous research on medical student attitudes toward general practice}

Wang et al (2012) surveyed 228 clinical undergraduate medical students and found roughly a third were not considering GP, felt GPs had low social status, and preferred other specialties. ${ }^{26}$ Zhang et al conducted a cross-sectional survey of medical students from three medical schools, with 2,402 valid responses. Attitudes about GP were overall positive, but interest in GP decreased as students progressed into higher grade levels. Students from rural backgrounds, more exposure to community reforms, personally held values and fit, and adequate income were predictive of willingness to work in communities. ${ }^{8}$

\section{Opportunity for a comparison between Chinese national and international}

\section{medical students}

The medical school of Peking University Health Science Center is one of the top ones in China. Within China, medical schools draw a relatively large number of international students, mostly from Asia. This unique situation of having a large cohort of international students affords the opportunity to make a cross-cultural comparison. Cross-cultural comparisons can accentuate features within and across groups that may not otherwise be obvious when focusing on only one group. ${ }^{27}$ Chinese students have largely been raised in a context devoid of GP, whereas international students have greater exposure to GP and thus a different lens for viewing GP. In light of promotion of GP as a national priority in China, the intent of this comparison is to better understand the challenges researchers face in promoting GP to medical students, especially Chinese nationals, the pool from which future GPs must come.

The purpose of this research was to examine first-year medical student attitudes toward GP in China, as this represents an area of research not previously investigated. In addition, we sought to compare the attitudes of Chinese students and international students to conduct a crosscultural comparison.

\section{Methods \\ Design}

We distributed a cross-sectional survey that was reviewed and approved by the Peking University Health Science Center ethics committee as exempt (IRB00001052-17002mian). 


\section{Theory}

Vauclair's values taxonomy from cross-cultural psychology provided theory underpinning this research. The taxonomy distinguishes between personal values and personal moral values, as well as social values and social moral values. ${ }^{27}$ In this study, the theory provides a framework for comparing what is personally and socially wanted, ie, desired, and what personally and socially ought to be (desirability) among Chinese national and international students.

\section{Setting}

This study was conducted at Peking University Health Science Center, a setting with a relatively large cohort of international medical students not typical of other universities in China.

\section{Participants}

There were 347 students in the first-year medical student class comprised of two sections, Chinese and international, the latter including "heritage" Chinese students, eg, from Hong Kong, Macau, and Taiwan, as well as international students from mostly Asian countries.

\section{Study instrument}

We first devised an English-language version of the survey, drawing heavily from Wright et al. ${ }^{10}$ We similarly used 5-point Likert-scale responses, and 23 items on career-choice predictors from Wright et al. ${ }^{10}$ As we wanted students to consider specific characteristics of GP, we added 7 items on work settings; 7 items on preferred age/gender groups; 10 items on attitudes about GP, and 14 items on attitudes about career and lifestyle. Demographic information was linked from the student's unique identifier. As not relevant for China, we did not include two items previously used by Wright et al (adequate income to eliminate debt, sooner deal with medical than social problems). ${ }^{10}$

\section{Translation}

The survey first was translated into Chinese by a fully bilingual investigator (QC) who noted any translation dilemmas, content that was difficult or awkward to translate. The translation was checked by a second bilingual investigator (SL), and the translation dilemmas were discussed and resolved in a discussion among three investigators (QC, SL, and MF). This interactive process is arguably better than translation and back-translation, which can miss nuanced differences. The instrument was then pilot- and cognitively tested with two GP residents, as individuals roughly similar to the target audience.

\section{Data-collection procedures}

Prior to distributing the questionnaire, we described the aim of the survey and explained that students could choose not to take it or finish it. By taking the survey, the students gave their consent to participate. Students took the 10-min survey in October 2016 and November 2016 using an online application prior to "Introduction to medicine" lecture. Students could respond using Chinese or English.

\section{Data analysis}

Using SPSS 21.0, descriptive statistics of the sample were calculated. The analysis also examined differences between responses from the Chinese national and international student classes, and differences by sex using Chisquare and independent sample $t$-tests as appropriate. After examining all the individual items, we considered implications at the personal level versus the social level between the Chinese national and international students.

\section{Results}

Of 347 eligible students from the first-year class, 335 participated (response rate 93.8\%): 258 (77\%) Chinese and $77(23 \%)$ international students (Table 1). Of the 77 international students, the most commonly represented countries were Japan (38\%), South Korea (17\%), Nepal $(10 \%)$, Sri Lanka (9\%), Guyana (4\%), and "other" $(22 \%)$. There were $180(54 \%)$ male and 155 (46\%) female students. All students had entered the host medical school on one of three tracks, with a majority of international students $(92 \%)$ enrolled in the 6-year program.

\section{Student willingness to work in specific medical settings}

The most highly ranked settings for both Chinese and international students were the operating room, inpatient ward, outpatient setting, and emergency room. The intensive care unit (ICU), patient's home, and delivery room were ranked as the locations of least interest by both groups (Table 2). Despite the similarity in rankings, international students were more willing to work in the outpatient, delivery room, ICU, emergency room, and patient home settings than Chinese students (all $P \leq 0.05$ ). The only 
Table I Demographics of participants

\begin{tabular}{|l|l|l|l|l|}
\hline & Overall (N=335) & Chinese students (N=258) & International students (N=77) & $\mathbf{X}^{\mathbf{2}} \mathbf{P}$ - value \\
\cline { 2 - 5 } & $\mathbf{n}(\%)$ & $\mathbf{n}(\%)$ & $\mathbf{n}(\%)$ & 0.16 \\
\hline Sex & & & $36(46.8)$ & \\
Male & $180(53.7)$ & $144(55.8)$ & $41(53.2)$ & $<0.001$ \\
Female & $155(46.3)$ & $114(44.2)$ & & $4(5.2)$ \\
\hline $\begin{array}{l}\text { Program type, n (\%) } \\
\text { 8-year program (PhD) }\end{array}$ & $97(29.0)$ & $93(36.1)$ & $71(92.2)$ & $2(2.6)$ \\
6-year program (BM) & $95(28.4)$ & $24(9.3)$ & $141(54.7)$ & \\
5-year program (BM) & $143(42.7)$ & $14)$ & \\
\hline
\end{tabular}

Table 2 Student willingness to work in various medical settings by nationality

\begin{tabular}{|l|l|l|l|l|l|}
\hline \multirow{2}{*}{ Factor evaluated } & \multicolumn{2}{l|}{ Chinese students (N=258) } & \multicolumn{2}{l|}{ International students (N=77) } & t-test $P$-value \\
\cline { 2 - 6 } & Rank & Mean/SD & Rank & Mean/SD \\
\hline Operating room & $\mathrm{I}$ & $4.15 \pm 0.95$ & 2 & $3.91 \pm 1.15$ & 0.07 \\
Inpatient ward setting & 2 & $3.79 \pm 0.93$ & 4 & $3.77 \pm 0.96$ & 0.82 \\
Outpatient setting & 3 & $3.74 \pm 0.98$ & 1 & $3.99 \pm 0.92$ & 0.05 \\
Emergency room & 4 & $3.46 \pm 1.15$ & 3 & $3.79 \pm 1.15$ & 0.03 \\
ICU & 5 & $3.36 \pm 1.11$ & 5 & $3.65 \pm 1.04$ & 0.05 \\
Patient's home & 6 & $2.85 \pm 1.23$ & 6 & $3.38 \pm 1.16$ & 0.001 \\
Delivery room & 7 & $2.58 \pm 1.13$ & 7 & $3.34 \pm 1.21$ & $<0.001$ \\
\hline
\end{tabular}

sex difference identified was women being more willing than men to work in the delivery room $(P=0.01)$.

\section{Student attitudes about willingness to provide different types of care and age groups they are willing to serve}

International students rated more highly than Chinese on their willingness to provide two types of care particularly emphasized in GP: preventive and palliative (all $P \leq 0.01$ ) (Table 3). International students also expressed greater interest in caring for age groups that distinguish GP care from general internal medicine, eg, care of babies, children, and women (all $P \leq 0.03$ ). There were no significant differences between international and Chinese students on care for adolescents, adult men, or the elderly. Male students were more willing to provide care for adult men, while female students were more willing to provide care for adult women and to provide care for chronic illness (all $P<0.01$ ).

\section{Factors associated with career choices}

For factors influencing career choice, five of the top six factors Chinese students ranked - social commitment, stable/secure future, flexibility within medicine, acceptable hours of practice, and keeping all career options open - were the same for international students (Table 4). Despite being ranked highly by both groups, social commitment was significantly higher for Chinese students and flexibility outside medicine was less important to international students (both $P=0.002$ ). Four of the five lowest-rated general factors assessed by the Chinese students - acceptable on-call schedule, supervisor recommended this career, emulating a physician known to me, and patient population is interesting/stimulating — were similarly rated lowly by international students. The lowest rated factor by Chinese students, focus on urgent care, was the third most highly rated factor by international students $(P<0.001)$

Of seven factors associated with other specialty/hospital-based care, five - interest in research, high income, status among colleagues, do not like uncertainty, and results of interventions are immediately available were among the seven most highly rated factors by Chinese students (Table 5). For international students, only two of these - interest in research and focus on inhospital care - were among the most highly rated. At the item level, international students ranked more highly than Chinese students on results of interventions being immediately available $(P=0.05)$ and focus on in-hospital care $(P<0.001)$, while Chinese students rated focus on 
Table 3 Student willingness to provide different types of care and to care for different age groups by nationality

\begin{tabular}{|c|c|c|c|c|c|}
\hline \multirow[t]{2}{*}{ Factor evaluated } & \multicolumn{2}{|c|}{ Chinese students $(\mathrm{N}=\mathbf{2 5 8})$} & \multicolumn{2}{|c|}{ International students $(\mathbf{N}=\mathbf{7 7})$} & \multirow[t]{2}{*}{$t$-test $P$-value } \\
\hline & Rank & Mean \pm SD & Rank & Mean \pm SD & \\
\hline \multicolumn{6}{|l|}{ Types of care interest } \\
\hline Acute care & I & $3.90 \pm 0.95$ & I & $3.87 \pm 0.95$ & 0.79 \\
\hline Chronic Care & 2 & $3.78 \pm 0.96$ & 3 & $3.65 \pm 0.96$ & 0.31 \\
\hline Preventive services & 3 & $3.30 \pm 1.13$ & 2 & $3.74 \pm 1.01$ & 0.003 \\
\hline Palliative care & 4 & $3.15 \pm 1.17$ & 4 & $3.52 \pm 1.07$ & 0.01 \\
\hline \multicolumn{6}{|l|}{ Age groups of interest } \\
\hline Care for adolescents & I & $3.78 \pm 0.98$ & 2 & $3.77 \pm 0.96$ & 0.94 \\
\hline Care for adult women & 2 & $3.72 \pm 0.94$ & I & $3.99 \pm 0.87$ & 0.03 \\
\hline Care for elderly & 3 & $3.69 \pm 0.91$ & 3 & $3.66 \pm 1.05$ & 0.82 \\
\hline Care for adult men & 4 & $3.61 \pm 1.00$ & 4 & $3.60 \pm 1.10$ & 0.93 \\
\hline Care for children & 5 & $3.07 \pm 1.26$ & 5 & $3.57 \pm 1.09$ & 0.002 \\
\hline Care for babies & 6 & $3.00 \pm 1.26$ & 6 & $3.49 \pm 1.05$ & 0.002 \\
\hline
\end{tabular}

Table 4 General factors influencing student top career choices by nationality

\begin{tabular}{|l|l|l|l|l|l|}
\hline \multirow{2}{*}{ Factor evaluated } & \multicolumn{2}{l|}{ Chinese students (N=258) } & \multicolumn{2}{l|}{ International students (N=77) } \\
\cline { 2 - 6 } & Rank & Mean \pm SD & Rank & Mean \pm SD \\
\hline Social commitment & $\mathrm{I}$ & $4.14 \pm 0.94$ & 2 & $3.77 \pm 1.01$ & 0.002 \\
Flexibility outside medicine & 2 & $3.92 \pm 1.08$ & 7 & $3.49 \pm 1.07$ & 0.002 \\
Stable/secure future & 3 & $3.90 \pm 1.07$ & 1 & $3.87 \pm 0.95$ & 0.83 \\
Flexibility inside of medicine (clinical/research) & 4 & $3.80 \pm 1.08$ & 4 & $3.55 \pm 1.15$ & 0.07 \\
Acceptable hours of practice & 5 & $3.58 \pm 1.20$ & 6 & $3.52 \pm 1.03$ & 0.68 \\
Keep all options open & 6 & $3.50 \pm 1.13$ & 5 & $3.53 \pm 0.98$ & 0.82 \\
Acceptable on-call schedule & 7 & $3.43 \pm 1.19$ & 10 & $3.39 \pm 1.05$ & 0.79 \\
Supervisors recommended this career this career & 8 & $3.26 \pm 1.17$ & 11 & $3.32 \pm 1.17$ & $3.40 \pm 1.07$ \\
To emulate a physician known to me & 9 & $3.24 \pm 1.27$ & 9 & $3.48 \pm 0.99$ \\
Patient population is interesting/stimulating & 10 & $3.20 \pm 1.20$ & 8 & $3.57 \pm 1.12$ \\
Focus on urgent care & $\mathrm{II}$ & $3.00 \pm 1.13$ & 3 & 0.39 \\
\hline
\end{tabular}

a narrower variety of problems as the lowest among all factors on importance. While significantly different from international students who scored more highly $(P=0.0006)$, even among the international students, this factor was rated among the least important and had only a moderate overall level of support.

Among five factors typically associated with GP, Chinese students rated three - focus on non-urgent care, wide variety of patient problems, and focus on patients in the community among the lowest (Table 5). For international students, three factors - health promotion, care of patients in the community, and wide variety of patient problems - were among their highest rated factors. At the item level, international students rated having a wide variety of patient problems $(P=0.001)$ and focus on patients in the community $(P<0.001)$, features associated with GP, higher than Chinese students. No significant sex differences were found.

\section{Medical student attitudes about general practice}

Chinese and international students had largely positive views of GPs, with most rankings on the Likert scale hovering around 4 (Table 6). With regard to differences, Chinese students endorsed GPs being needed in rural areas in China $(P<0.001)$, supported by the Chinese government $(P=0.02)$, and respected by society $(P=0.002)$ more highly than their international peers. However, Chinese students showed lower levels of agreement with the assertions that GPs are specialists $(P<0.001)$, and that GP is a good career choice for women $(P=0.003)$. 
Table 5 Influence of specialty-related factors on students' top career choices by nationality

\begin{tabular}{|c|c|c|c|c|c|c|}
\hline \multirow[t]{2}{*}{ Specialty type } & \multirow[t]{2}{*}{ Factor evaluated } & \multicolumn{2}{|c|}{$\begin{array}{l}\text { Chinese students } \\
(\mathrm{N}=\mathbf{2 5 8})\end{array}$} & \multicolumn{2}{|c|}{$\begin{array}{l}\text { International students } \\
(\mathrm{N}=77)\end{array}$} & \multirow[t]{2}{*}{$P$-value } \\
\hline & & Rank & Mean \pm SD & Rank & Mean \pm SD & \\
\hline $\begin{array}{l}\text { Other specialty/hospital- } \\
\text { related factors }\end{array}$ & $\begin{array}{l}\text { Interest in research } \\
\text { High-income potential } \\
\text { Status among my colleagues } \\
\text { Don't like uncertainty } \\
\text { Results of interventions immediately available } \\
\text { Focus on in-hospital care } \\
\text { More narrow variety of patient problems }\end{array}$ & $\begin{array}{l}1 \\
2 \\
5 \\
6 \\
7 \\
9 \\
12\end{array}$ & $\begin{array}{l}4.04 \pm 1.05 \\
3.89 \pm 1.06 \\
3.50 \pm 1.17 \\
3.31 \pm 1.22 \\
3.23 \pm 1.16 \\
3.13 \pm 1.13 \\
2.27 \pm 1.06\end{array}$ & $\begin{array}{l}1 \\
4 \\
8 \\
12 \\
5 \\
2 \\
11\end{array}$ & $\begin{array}{l}3.79 \pm 1.10 \\
3.64 \pm 1.11 \\
3.47 \pm 1.10 \\
3.18 \pm 1.08 \\
3.52 \pm 0.97 \\
3.71 \pm 0.90 \\
3.22 \pm 1.05\end{array}$ & $\begin{array}{l}0.07 \\
0.07 \\
0.81 \\
0.41 \\
0.05 \\
<0.001 \\
0.0006\end{array}$ \\
\hline $\begin{array}{l}\text { General practice-related } \\
\text { factors }\end{array}$ & $\begin{array}{l}\text { Health promotion is important } \\
\text { Long-term relationship with my patients } \\
\text { Focus on nonurgent care } \\
\text { Wide variety of patient problems } \\
\text { Focus on patients in the community }\end{array}$ & $\begin{array}{l}3 \\
4 \\
8 \\
10 \\
11\end{array}$ & $\begin{array}{l}3.75 \pm 1.14 \\
3.56 \pm 1.05 \\
3.17 \pm 1.18 \\
3.02 \pm 1.07 \\
2.64 \pm 1.22\end{array}$ & $\begin{array}{l}3 \\
9 \\
10 \\
7 \\
6\end{array}$ & $\begin{array}{l}3.70 \pm 1.03 \\
3.38 \pm 1.04 \\
3.26 \pm 0.99 \\
3.48 \pm 1.06 \\
3.49 \pm 1.08\end{array}$ & $\begin{array}{l}0.73 \\
0.18 \\
0.56 \\
0.001 \\
<0.001\end{array}$ \\
\hline
\end{tabular}

Table 6 Medical student attitudes about status of GP in China and about GPs by nationality

\begin{tabular}{|l|l|l|l|l|l|}
\hline \multirow{2}{*}{ General practice ... } & \multicolumn{2}{l|}{ Chinese students (N=258) } & \multicolumn{2}{l|}{ International students (N=77) } & \multirow{2}{*}{ P-value } \\
\cline { 2 - 5 } & Rank & Mean \pm SD & Rank & Mean \pm SD \\
\hline Physicians are needed in rural areas in China & $I$ & $4.34 \pm 0.74$ & 1 & $3.99 \pm 0.77$ & $<0.001$ \\
Physicians are supported by the Chinese government & 2 & $4.19 \pm 0.80$ & 6 & $3.94 \pm 0.83$ & 0.02 \\
Physicians are respected by society & 3 & $4.17 \pm 0.84$ & 7 & $3.84 \pm 0.84$ & 0.002 \\
Physicians are respected by patients & 4 & $4.16 \pm 0.86$ & 3 & $3.97 \pm 0.83$ & 0.09 \\
Physicians are respected by nurses & 5 & $4.11 \pm 0.82$ & 1 & $3.99 \pm 0.85$ & 0.24 \\
Physicians are respected by other specialists & 6 & $4.06 \pm 0.87$ & 3 & $3.97 \pm 0.79$ & 0.43 \\
Physicians are needed in urban areas in China & 7 & $3.86 \pm 0.92$ & 5 & $3.96 \pm 0.75$ & 0.36 \\
Is good career choice for men & 8 & $3.47 \pm 0.90$ & 10 & $3.66 \pm 1.03$ & $3.75 \pm 0.86$ \\
Is a good career choice for women & 9 & $3.41 \pm 0.90$ & 8 & $3.71 \pm 0.90$ \\
Physicians are specialists & 10 & $2.96 \pm 1.13$ & 9 & 0.003 \\
\hline
\end{tabular}

\section{Medical student attitudes about a general practice career and lifestyle attributes}

There were few differences on individual items between Chinese and international students relative to lifestyle attributes (Table 7). International students agreed more strongly that a GP career will allow a healthy lifestyle $(P=0.04)$, and favorable working hours $(P=0.01)$. Despite their low ratings on many aspects of GP, Chinese students rated at a higher level than international students on GP fitting with personality $(P<0.001)$, GPs providing continuous and comprehensive care $(P=0.01)$, and GPs needing more broad knowledge $(P=0.002)$. Chinese students held more negative perceptions about GP, eg, too much simple and repetitive work $(P=0.01)$, and the field having a low level of research $(P=0.01)$.

\section{Discussion}

These findings about first-year medical student attitudes toward GP in China and the comparison of Chinese and international students expand the sparse literature exploring medical students' attitudes toward training preference. ${ }^{8,28}$ The findings confirm previous research showing students generally prefer other specialties. ${ }^{26}$ Still, these results, based on understanding of specific aspects of the discipline and recognition of its social importance, suggest at least some students are hearing the government's emphasis on GP.

Still, international students endorsed more features consistent with GP than their Chinese counterparts, eg, the clinical setting, range of ages cared for, communitybased work, breadth of problems, and GP-associated care, such as preventive services and palliative care. It is unclear 
Table 7 Medical student attitudes about a GP career and lifestyle attributes by nationality

\begin{tabular}{|c|c|c|c|c|c|}
\hline \multirow[t]{2}{*}{ General practice career... } & \multicolumn{2}{|c|}{ Chinese students $(\mathrm{N}=\mathbf{2 5 8})$} & \multicolumn{2}{|c|}{ International students $(\mathbf{N}=77)$} & \multirow[t]{2}{*}{ P-value } \\
\hline & Rank & Mean \pm SD & Rank & Mean \pm SD & \\
\hline Needs broad knowledge & I & $4.32 \pm 0.77$ & I & $4.00 \pm 0.83$ & 0.002 \\
\hline Fits with my personality & 2 & $4.31 \pm 0.94$ & 5 & $3.84 \pm 1.00$ & $<0.001$ \\
\hline Can provide continuous and comprehensive care & 3 & $4.17 \pm 0.74$ & 3 & $3.91 \pm 0.83$ & 0.01 \\
\hline Provides a sense of accomplishment & 4 & $3.80 \pm 0.83$ & 8 & $3.78 \pm 0.75$ & 0.86 \\
\hline Can allow a healthy lifestyle & 5 & $3.77 \pm 0.89$ & I & $4.00 \pm 0.79$ & 0.04 \\
\hline Allows being a good parent & 6 & $3.74 \pm 0.90$ & 6 & $3.8 I \pm 0.8 I$ & 0.55 \\
\hline Has a good physician-patient relationship & 7 & $3.73 \pm 0.93$ & 4 & $3.86 \pm 0.84$ & 0.28 \\
\hline Is a respected professional & 8 & $3.68 \pm 0.97$ & 8 & $3.78 \pm 0.88$ & 0.43 \\
\hline Allows good career advancement & 9 & $3.67 \pm 0.94$ & 12 & $3.68 \pm 0.80$ & 0.97 \\
\hline Provides a good income & 10 & $3.57 \pm 0.91$ & 11 & $3.70 \pm 0.80$ & 0.25 \\
\hline Allows enjoyment of personal time & 11 & $3.53 \pm 1.01$ & 10 & $3.73 \pm 0.85$ & 0.12 \\
\hline Has good working hours & 12 & $3.50 \pm 0.91$ & 6 & $3.8 I \pm 0.83$ & 0.01 \\
\hline Has too much simple and repetitive work & 13 & $3.23 \pm 0.99$ & 13 & $3.55 \pm 0.77$ & 0.01 \\
\hline Has a low level of research level & 14 & $2.95 \pm 0.97$ & 14 & $3.27 \pm 0.85$ & 0.01 \\
\hline
\end{tabular}

whether Chinese students' stronger endorsement of working in the operating theater and providing acute and chronic care services reflects less exposure in Chinese social or educational systems. Differences could stem from sociocultural views about scope of physician work. As medicine has primarily been hospital-based over the past three to four decades in China, students might have difficulty conceptualizing work in outpatient practice. We postulate that international students who have had more exposure to outpatient, community-based practice, have been exposed to a broader sociocultural framework consistent with GP. Further research is needed to understand practice characteristics, eg, age range, sex, and type of care, ie, preventive, acute, chronic, and palliative, that Chinese students consider associated with GP.

\section{A cross-cultural interpretation}

Vauclair's theory provides a framework for deeper interpretation of these results relative to what is personally and socially desirable between Chinese national and international students. ${ }^{27}$ At the personal level, international students more strongly endorsed features of GP as being personally desirable to them. In contrast, Chinese national students did not endorse as desirable nearly as many features that characterize GP. As for the social desirability of GP, international students felt less strongly about the social importance of GP to China, while Chinese students strongly recognized and endorsed the desirability of GP for Chinese society. These differences may reflect a familiarity of international students with GP from their home countries, as they were actually able to envision a GP who provided preventive, urgent, and chronic care to a spectrum of all patient ages. In contrast, GP may still seem more abstract at a personal level to Chinese national students, who would likely not have experienced personally an encounter with a GP physician that provided primary care.

\section{Implications for general practice policy in China}

As acknowledged by the Chinese government, ${ }^{17}$ a challenge in China is to maintain the interest of students who have indicated GP as having appeal. The implications of this crosscultural comparison highlight that Chinese government policies and medical education efforts and messages that emphasize why GP is socially desirable seem to be reaching a substantial number of Chinese medical students. However, there remains a gap between what is socially desirable and what is perceived as personally desirable. Emphasizing social benefits of GP alone are not likely to compel students to pursue GP. Rather, policy and educational interventions designed to increase student interest in GP should focus specifically on appealing to students at a personal level the factors that characterize GP.

Part of this challenge requires dispelling myths, such as that GPs are not specialists. The government and the specialty need to become better at articulating why GPs are specialists, eg, expertise managing common problems, multiple chronic conditions, mental health issues, and population health. Emphasizing the rewards of caring for babies, children, and women could enhance student interest, particularly in light of the new policy permitting up to two 
children per family. ${ }^{29}$ Chinese students' preferences for working in hospitals emphasizes the need to make community-based practice more appealing. Implementing GP curricula and courses during medical school are interventions previously shown to be promising for encouraging medical student interest in GP. ${ }^{23-26}$ A 2018 Chinese State Council announcement includes planning for improving GPphysician salary and social status to help address concerns about poor quality and low payment. ${ }^{15,19,20}$

\section{Study findings in the international context} These findings are consistent with many aspects of the international literature on attitudes about family medicine/GP, eg, the valuing of GP as a national policy, as in the UK and Spain. ${ }^{6,12}$ In contrast to Germany, ${ }^{11}$ female sex was not associated with GP preference, but as found previously in Canada, lifestyle issues contributed. ${ }^{10}$ Conviction about the social importance of GP is consistent with previous research as well. ${ }^{7,11}$ Schneider et al similarly found limited personal interest in GP among medical students in three Bavarian universities, but the same tendency for positive attitudes about GP's social desirability. ${ }^{30}$

\section{Limitations}

The stability of the participants' preferences obtained in crosssectional research remains uncertain. The optimism for interest in GP should be interpreted with caution, as the international literature suggests that without an unequivocal social valuing of GP, interest will likely wane as these students progress through the curriculum. ${ }^{8,13,14,31}$ As the study was conducted in a leading academic medical institution, caution may be needed in extrapolating the findings across China. However, the challenge of raising interest in GP among Chinese national medical students is not likely to differ much across institutions, since it remains a new, incompletely acknowledged specialty. Therefore, we believe these findings are relevant to institutions across China working to introduce GP into the curriculum and promote student interest in GP. Moreover, as one of the leading medical institutions and one of the relative few that has a GP department in China, Peking University Health Science Center plays a vital role in recommending GP-education developments to the policy-makers, and promoting training of GP teachers in China.

\section{Conclusion}

This research addresses how entry-level medical students perceive GP in China. While recognizing the social desirability of a GP workforce in China, few endorse as personally desirable dimensions typical of GP. These findings are encouraging in that some entry-level students are at least considering GP and hearing about its importance to society. Future opportunities for research include expanding investigations into a larger population of students, understanding student perceptions about features of GP, and examining stability of preferences over time.

\section{Practice points}

- Educators need to articulate the unique characteristics and work that frame GP as a specialty.

- Public policy initiatives may work for conveying the social importance of GP, but need development relative to motivating student choice of the specialty.

- Health policies and educational interventions need to focus more on how GP can be a personally desirable and rewarding career.

\section{Acknowledgments}

The authors acknowledge all the participating students, and Dr. Julie Phillips who provided helpful comments on an early draft of the manuscript. Financial support was recieved: Dr. Fetters by the Fulbright Distinguished Chair in the Social Sciences Program, and Dr. Chen by the Research Fund for Youth, Institute for Medical Humanities, Peking University.

\section{Disclosure}

The authors report no conflicts of interest in this work.

\section{References}

1. Starfield B. Primary care and health. JAMA. 1991;266:2268-2271.

2. Starfield B. Is primary care essential? Lancet. 1994;344:1129-1133.

3. Starfield B. Is US health really the best in the world? JAMA. 2000;284:483-485.

4. Bennett KL, Phillips JP. Finding, recruiting, and sustaining the future primary care physician workforce: a new theoretical model of specialty choice process. Acad Med. 2010;85:S81-S8. doi:10.1097/ ACM.0b013e3181ed4bae

5. Garrett EA, Dietrich AJ. Students' evolving attitudes toward family medicine and specialty choices at one medical school. Acad Med. 1991;66:625-627.

6. Henderson E, Berlin A, Fuller J. Attitude of medical students towards general practice and general practitioners. $\mathrm{Br} J$ Gen Pract. 2002;52:359-363.

7. Saigal P, Takemura Y, Nishiue T, Fetters MD. Factors considered by medical students when formulating their specialty preferences in Japan: findings from a qualitative study. BMC Med Educ. 2007;7:31. doi:10.1186/1472-6920-7-31

8. Zhang L, Bossert T, Mahal A, Hu G, Guo Q, Liu Y. Attitudes towards primary care career in community health centers among medical students in China. BMC Fam Pract. 2016;17:75-83. doi:10.1186/ s12875-016-0472-5 
9. Williamson M, Gormley A, Bills J, Farry P. The new rural health curriculum at Dunedin school of medicine: how has it influenced the attitudes of medical students to a career in rural general practice? N Z Med J. 2003;116(1179):U537.

10. Wright B, Scott I, Woloschuk W, Brenneis F, Bradley J. Career choice of new medical students at three Canadian universities: family medicine versus specialty medicine. CMAJ. 2004;170:1920-1924.

11. Kruschinski C, Wiese B, Eberhard J, Hummers-Pradier E. Attitudes of medical students towards general practice: effects of gender, a general practice clerkship and a modern curriculum. GMS Z Med Ausbild. 2011;28. doi:10.3205/zma000755

12. Zurro AM, Villa JJ, Hijar AM, Tuduri XM, Puime ÁO, Alonso-Coello P. Medical student attitudes towards family medicine in Spain: a statewide analysis. BMC Fam Pract. 2012;13:47-54. doi:10.1186/1471-2296-13-47

13. Ayuso-Raya MC, Escobar-Rabadán F, López-Torres-Hidalgo J, Montoya-Fernández J, Téllez-Lapeira JM, Campa-Valera F. Predictors for choosing the specialty of family medicine from undergraduate knowledge and attitudes. Sao Paulo Med J. 2016;134:306-314. doi:10.1590/1516-3180.2015.02581002

14. Kruschinski C, Wiese B, Hummers-Pradier E. Attitudes towards general practice: a comparative cross-sectional survey of 1 st and 5 th year medical students. GMS ZMed Ausbild. 2012;29(5):Doc71. doi:10.3205/zma000841

15. Wu D, Lam TP. At a crossroads: family medicine education in China. Acad Med. 2017;92:185-191. doi:10.1097/ACM.0000000000001512

16. Ge Y, Xu J, Zhou Y, Qian D. 我国全科医学发展历史与现状分析 [History and present situation of development of general practice in China]. Chinese. Chin Gen Pract. 2013;16:2201-2203.

17. National development and reform commission $\mathrm{MoH}$, state comission office of public sectors reform, ministry of education, ministry of finance, ministry of human resources and social security of the People's Republic of China,. 以全科医生为重点的基层医疗卫生队 伍建设规划 [General practitioner as the focus of the primary health care team planning]. Chinese; 2010. Available from: http://www.gov.cn/gzdt/ 2010-04/02/content_1572090.htm. Accessed September 29, 2017.

18. National health and family planning commission of the People's Republic of China. 十三五” 全国卫生计生人才发展规划 [The 13th national five-year place for national health and family planning]. Chinese. Chin Nurs Manage. 2017;17:145-149.

19. General office of the state council. 国务院办公厅关于改革完善全 科医生培养与使用激励机制的意见 [opinions of the general office of the state council on reforming and perfecting general physician training and use of incentive mechanism]. Chinese; 2018. Available from: http://www.gov.cn/zhengce/content/2018-01/24/content 5260073.htm. Accessed January 28, 2018.
20. Wu D, Lam TP, Lam KF, Zhou XD, Sun KS. Public views towards community health and hospital-based outpatient services and their utilisation in Zhejiang, China: a mixed methods study. BMJ Open. 2017;7:e017611. doi:10.1136/bmjopen-2017-017611

21. Wong WC, Jiang S, Ong JJ, et al. Bridging the gaps between patients and primary care in China: a nationwide representative survey. Ann Fam Med. 2017;15:237-245. doi:10.1370/afm.2034

22. Lian S, Chen Q, Yao M, Chi C, Fetters M. Training pathways to wroking as a general practitioner in China. Fam Med. 2019;51:262-270. doi:10.22454/FamMed.2019.329090

23. Yong B, Gao X, Xu J, et al. 高校医学生对社区医学认知的比较研 究和有关问题的探讨 [Acquaintanceship comparative study in community health service for medico and investigation on its relational issues]. Chinese. Med Soc (Berkeley). 2001;14:5-9.

24. Sun R, Li N, Chen D, et al. 北京、成都两地医学生对全科医学规 范化教育态度的调查 [The survey of Beijing and Chengdu medical students' attitudes about general medicine standardized education]. Chinese. Chin Gen Pract. 2004;7:298-299.

25. Hu C-L, Li Y-C, Tao X-Y. 不同课程设置的临床医学生对社区导向 医学教育的态度 [Attitude differences about community-oriented medical education in clinical medical students]. Chinese. Chin Gen Pract. 2007;17:019.

26. Wang H-L, Zhao Y-L, Lu X-Q. Investigation of knowledge and attitude to general practice of clinical medical undergraduates. Chin J Gene Pract. 2012;12:060.

27. Vauclair C-M. Measuring cultural values at the individual-level: considering mortality in cross-cultural value research. Ram. 2009;10:60-83.

28. Liang D, Tang C-X. The specialty choice of medical students in China: a stated preference experiment. BMC Med Educ. 2016;16:107-116. doi:10.1186/s12909-016-0619-Z

29. Central People's Government of the People's Republic of China. 中 共中央关于全面深化改革若干重大问题的决定 [decision of the central committee of the communist party of China on deepening reform of some major issues]. Chinese; 2013. Available from: http://www.gov.cn/jrzg/2013-11/15/content_2528179.htm. Accessed September 29, 2017.

30. Schneider A, Karsch-Völk M, Rupp A, et al. Predictors of a positive attitude of medical students towards general practice-a survey of three Bavarian medical faculties. GMS Z Med Ausblld. 2013;30(4): Doc45.

31. Burack JH, Irby DM, Carline JD, Ambrozy DM, Ellsbury KE, Stritter FT. A study of medical students' specialty-choice pathways: trying on possible selves. Acad Med. 1997;72:534-541.
Advances in Medical Education and Practice

\section{Publish your work in this journal}

Advances in Medical Education and Practice is an international, peerreviewed, open access journal that aims to present and publish research on Medical Education covering medical, dental, nursing and allied health care professional education. The journal covers undergraduate education, postgraduate training and continuing medical education including emerging trends and innovative models linking education, research, and health care services. The manuscript management system is completely online and includes a very quick and fair peer-review system. Visit http://www.dovepress.com/testimonials.php to read real quotes from published authors. 